\title{
Dechlorination and decomposition of chloroform induced by glow discharge plasma in an aqueous solution
}

\author{
Yongjun Liu ${ }^{1,2 *}$ John C. Crittenden², Lei Wang ${ }^{3}$, Panliang Liu $^{2}$ \\ ${ }^{1}$ College of Environmental Science \& Engineering, Dalian Maritime University, Dalian 116026, $P$. \\ R. China; E-mail: lyjglow@ sohu.com; Tel. and Fax: 86-411-84727670 \\ ${ }^{2}$ Brook Byers Institute for Sustainable Systems, Georgia Institute of Technology, Atlanta 30332, \\ United States \\ ${ }^{3}$ College of Environmental Science \& Engineering, Xiamen University of Technology, Xiamen \\ 361024, P. R. China
}

\begin{abstract}
In this study, efficient dechlorination and decomposition of chloroform (CF) induced by glow discharge plasma (GDP) in contact with a sodium sulfate solution was investigated. Intermediate byproducts were determined by ionic chromatography and headspace gas chromatography, respectively. Results showed that CF can be effectively dechlorinated and decomposed under the action of GDP. Both removal and dechlorination of $\mathrm{CF}$ increased with increasing $\mathrm{pH}$ and with addition of hydroxyl radical scavengers to the solution. Addition of $\mathrm{H}_{2} \mathrm{O}_{2}$ to the solution slightly decreased the CF removal. Formic acid, oxalic acid and dichloromethane were determined as the major intermediate byproducts. Final products were carbon dioxide and hydrochloric acid. Hydrated electrons were the most likely active species responsible for initiation of the dechlorination, and hydroxyl radicals may be the ones for the oxidation of the organic intermediate byproducts. Hydrolyses of the chloromethyl radicals contributed much in the mineralization of the organic chlorine. Reaction mechanism was proposed based on the dechlorination kinetics and the distribution of intermediate byproducts.
\end{abstract}

Keywords: non-thermal plasma; chloroform; dechlorination; reaction mechanism 


\section{Introduction}

Chloroform $\left(\mathrm{HCCl}_{3}, \mathrm{CF}\right)$ is widely used as solvents and as chemical intermediates [1]. During chlorination of water or wastewater (at the outlet of wastewater plant), $\mathrm{CF}$ is usually produced as a toxic byproduct $[2,3]$. $\mathrm{CF}$ is an omnipresent aqueous contaminant due to its carcinogenicity, environmental persistence and high solubility $(8.22 \mathrm{~g} / \mathrm{l}$ at $293 \mathrm{~K})[1,4]$.

$\mathrm{CF}$ is toxic to microbes and is not susceptible to metabolic transformations [5]. Granular activated carbon (GAC) adsorption was often employed to remove CF from aqueous solutions [6]. However, the GAC adsorption is just a physical process without eventually decomposing it into harmless products. In addition, CF is hardly decomposed by advanced oxidation processes such as Fenton's reagent [7] because of its low reactivity towards the hydroxyl radicals $(\bullet \mathrm{OH})$ [8]. Sono-oxidation [9] and $\mathrm{TiO}_{2}$ photo-catalysis $[10,11]$ have been attempted for $\mathrm{CF}$ decomposition, but the two processes suffer either the process complexity or the low energy utilization efficiency. CF decomposition by electron beam (EB) irradiation has been investigated [12]. However, experimental and operating costs of EB radiation are usually prohibitively high. Therefore, development of alternative processes for $\mathrm{CF}$ mineralization is necessary.

Glow discharge plasma (GDP) in aqueous solution is also called contact glow discharge electrolysis (CGDE) [13, 14]. It is an electrical process where plasma is sustained by glow discharges between a pointed electrode and the surface of an electrolytic solution contacting with it. When normal electrolysis is carried out in an 
electrolytic solution with a point-to-plane electrode configuration, a sheath of vapor will be generated around the tip of the pointed electrode due to Ohmic heating. When the applied voltage is sufficiently high, the vapor breakdowns and GDP occurs. In GDP, charged particles in the gaseous plasma are accelerated due to the steep potential gradient and collide with liquid water molecules leading to the formation of various active species such as $\bullet \mathrm{OH}$ radicals [15], hydrogen atoms $(\cdot \mathrm{H})[16]$ and hydrated electrons $\left(\mathrm{e}_{\mathrm{aq}}{ }^{-}\right)[17]$, a process being analogous to what occurring in ionizing radiation of water [13]. Due to its relatively low discharge voltage, easy operation and no requirement of special power source, GDP has received considerable investigations from environmental researchers in recent pasts [14, 18-21].

Previous studies of GDP were mainly focused on the use of $\bullet \mathrm{OH}$ radicals to oxidize the aromatic compounds. The roles of its reducing species played in the process of pollutant removal were rarely reported [22, 23]. In this report, an attempt was made to use GDP to dechlorinate and decompose CF in aqueous solution, focused mainly on the optimizing the experimental conditions and the reaction mechanism. To the best of our knowledge, there is little information of using GDP for decomposing chlorinated methanes in aqueous media.

\section{Experimental}

Experimental assembly consisted of a DC high-voltage power source and a cylindrical glass reactor. The reactor is shown in Fig.1.

\section{(Fig.1)}

The anode was a pointed Pt wire sealed into a glass tube. The cathode was a 
stainless steel plate placed in another glass tube and separated from the anodic compartment by a sintered glass frit of medium porosity. The reaction vessel was coated by a water jacket, where temperature of the solution in the reactor was maintained at $298 \pm 2 \mathrm{~K}$ by running tap water. $\mathrm{CF}$ was dissolved in a sodium sulfate solution (with conductivity about $2.3 \mathrm{mS} / \mathrm{cm}$ ) and $150-\mathrm{ml}$ portion was poured into the reaction for treatment. Solution $\mathrm{pH}$ was adjusted with dilute sulfuric acid or sodium hydroxide to the expected value. Prior to each run, the point anode was dipped into the solution at ca. $2.0 \mathrm{~mm}$. The applied voltage was adjusted to the desired value to commence the discharge. In most cases, the applied voltage was $500 \mathrm{~V}$ and the current was kept within $100 \pm 2 \mathrm{~mA}$.

During the discharge, solution in the reactor was stirred persistently with a stirring bar and aliquots were periodically sampled out for analyses. Organic acids and chloride ion $\left(\mathrm{Cl}^{-}\right)$were identified and determined by ionic chromatography (IC, DIONEX ICS-1100) combined with an IonPac AS-23 separation column. An aqueous solution of dilute $\mathrm{KOH}(10.0 \mathrm{mmol} / \mathrm{L})$ was used as the mobile phase. The flow rate was $1.0 \mathrm{ml} / \mathrm{min}$. CF and the volatile organic byproducts were identified and determined by a headspace gas chromatography coupled with an electron capture detector (GC, SHIMADZU GC-2010). Sampling solutions (10.0 ml) were transferred into the headspace bottles and sustained for 20 min under the stationary temperature of $323 \mathrm{~K}$ in a water bath. Then $1.0 \mathrm{ml}$ portion of the gas above the solution was extracted with a headspace syringe $(2.5 \mathrm{ml})$ after piercing the septa and was injected into the GC. Operation conditions of GC are: injection temperature, $473 \mathrm{~K}$; detector 
temperature, $523 \mathrm{~K}$; carrier gas flow rate, $3.0 \mathrm{ml} / \mathrm{min}$; split ratio, 1:50; column gas flow rate, $1.0 \mathrm{ml} / \mathrm{min}$; make-up gas flow rate, $30 \mathrm{ml} / \mathrm{min}$; oven temperature was held isothermally at $313 \mathrm{~K}$ for $4 \mathrm{~min}$ and then ramped to $363 \mathrm{~K}$ at a rate of $293 \mathrm{~K} / \mathrm{min}$, further to $423 \mathrm{~K}$ at a rate of $303 \mathrm{~K} / \mathrm{min}$ for $1.0 \mathrm{~min}$. The amount of total organic carbon (TOC) was measured by a TOC analyzer (SHIMADZU TOC-VCSH). The organic intermediate byproducts were also identified by GC-MS (QP2010 Ultra).

\section{Results and discussions}

\section{1 $\mathrm{CF}$ removal and $\mathrm{Cl}^{-}$generation}

Dechlorination and decomposition of CF proceeded smoothly when the solution containing CF was exposed to GDP. Typical curves for the concentration variations of CF, TOC and $\mathrm{Cl}^{-}$during GDP treatment are shown in Fig.2.

\section{(Fig.2)}

As indicated from Fig.2, the amount of TOC and that of CF decreased monotonically while concentration of the generated $\mathrm{Cl}^{-}$increased gradually with increasing discharge time. After 300 min of discharge, about $73 \%$ of CF was removed and $70 \%$ of TOC disappeared and $1.78 \mathrm{mM}$ of $\mathrm{Cl}^{-}$was generated. It can be also observed from Fig.2 that the decay rate of TOC was less than that of CF, indicating that some organic intermediate byproducts formed during the discharge treatment. In order to clarify the chlorine balance, variation of $\left[\mathrm{Cl}^{-}\right] /\left([\mathrm{CF}]_{0}-[\mathrm{CF}]\right)$ with discharge time calculated from Fig.2 are presented in Fig.3.

As shown in Fig.3, the ratio between the amount of the generated $\mathrm{Cl}^{-}$and that of the CF eliminated was close to $3: 1(2.8 \sim 2.9: 1$ in the figure $)$ and increased with 
discharge time. This implies that very little chlorinated organic byproducts were formed during the discharge and that the formed chlorinated organic byproducts can also be dechlorinated by GDP. Detailed information concerning the mechanism of byproducts formation and dechlorination will be discussed in section 3.5. After 400 min of discharge, CF was completely eliminated and dechlorinated with $98.5 \%$ of TOC removed, indicating that $\mathrm{CF}$ can be efficiently transformed to $\mathrm{Cl}^{-}$and inorganic carbon under the action of GDP.

\section{(Fig.3)}

\subsection{Effect of applied voltage on the removal and dechlorination of CF}

Figure 4 shows the effect of applied voltage on the removal of $\mathrm{CF}$ and generation of $\mathrm{Cl}^{-}$with 60 min of treatment.

\section{(Fig.4)}

It can be observed from Fig. 4 that both the removal of $\mathrm{CF}$ and the generation $\mathrm{Cl}^{-}$ increased slightly with increasing applied voltage in the rang of 200-400V and sharply increased with increasing applied voltage from $400 \mathrm{~V}$ to $550 \mathrm{~V}$. For example, at $200 \mathrm{~V}$, only $2.1 \%$ of $\mathrm{CF}$ was removed and $0.03 \mathrm{mM} \mathrm{Cl}^{-}$was generated, while approximately $37 \%$ of $\mathrm{CF}$ was removed and $0.9 \mathrm{mM} \mathrm{Cl}^{-}$was generated in the case of $500 \mathrm{~V}$. This is because the discharge is not fully developed when the applied voltage is below $450 \mathrm{~V}$, where the amount of the active species produced for $\mathrm{CF}$ dechlorination and decomposition was small, and the removal of $\mathrm{CF}$ and the generation of $\mathrm{Cl}^{-}$were both trace $[13,16]$. When the voltage was lower than $150 \mathrm{~V}$, no appreciable CF degradation was observed (not shown in the figure), indicating that direct $\mathrm{CF}$ reduction at the 
cathode was negligible. When the applied voltage was higher than $550 \mathrm{~V}$, the platinum anode showed the signs of melting. Therefore, $500 \mathrm{~V}$ was chosen as the optimum applied voltage in the following experiments.

\subsection{Effect of $\mathrm{pH}$ on the removal and dechlorination of $\mathrm{CF}$}

$\mathrm{pH}$ often played an important role in water and wastewater treatment. In order to better elucidate the role of $\mathrm{pH}$ in $\mathrm{CF}$ mineralization, $\mathrm{pH}$ variations under different initial $\mathrm{pH}$ values $\left(\mathrm{pH}_{0}\right)$ during the GDP treatment are presented in Fig.5.

\section{(Fig.5)}

As shown in Fig.5, whenever the $\mathrm{pH}_{0}$ was, the solution $\mathrm{pH}$ dropped with discharge time. When $\mathrm{pH} 0$ was 11.0 , the $\mathrm{pH}$ dropped gradually with discharge time. When $\mathrm{pH} 0$ was 7.0 , the $\mathrm{pH}$ decreased rapidly within $10 \mathrm{~min}$ and then fell slowly with discharge time. In the case of $\mathrm{pH}_{0} 4.0$, the $\mathrm{pH}$ declined little in the whole process. The above phenomena can be explained by the fact that hydrochloric acid $(\mathrm{HCl})$, carbon dioxide $\left(\mathrm{CO}_{2}\right)$ and organic acids were generated during the discharge treatment (c.f. section 3.5). When $\mathrm{pH}_{0}$ was high (11.0), $\mathrm{HCl}, \mathrm{CO}_{2}$ and organic acids dissolved in the solution and reacted with the hydroxide ion. With prolonging discharge time, carbonate/bicarbonate buffer formed in the solution, which inhibited the sharp decrease of $\mathrm{pH}$. As a result, the $\mathrm{pH}$ dropped smoothly with discharge time in the whole process. When $\mathrm{pH}_{0}$ was $7.0, \mathrm{HCl}$ and organic acids dissolved and dissociated in the solution and a steep decrease of $\mathrm{pH}$ was observed. When dropped to 4.0, the $\mathrm{pH}$ varied slowly because the acid buffering of the solution, as in the case of $\mathrm{pH}_{0}$ being 4.0. Fig.6 shows the removal of $\mathrm{CF}$ and the generation of $\mathrm{Cl}^{-}$with 60 min of 
discharge treatment under different $\mathrm{pH}_{0}$.

\section{(Fig.6)}

As presented in Fig.6, both the removal of $\mathrm{CF}$ and the yield of $\mathrm{Cl}^{-}$increased with increasing $\mathrm{pH}_{0}$. When $\mathrm{pH}_{0}$ was $3.0,25 \%$ of $\mathrm{CF}$ was removed and $0.58 \mathrm{mM} \mathrm{Cl}^{-}$formed, whereas when the $\mathrm{pH}_{0}$ was increased to $11.0,42.5 \%$ of $\mathrm{CF}$ was removed and $1.02 \mathrm{mM}$ $\mathrm{Cl}^{-}$formed with the same discharge time. The phenomena can be explained as follows.

In GDP of aqueous solutions, liquid water molecules were decomposed by the incoming positive ions $\left(\mathrm{H}_{2} \mathrm{O}_{\text {gas }}{ }^{+}\right)$from the gaseous plasma into the following active species [13]:

$$
\mathrm{nH}_{2} \mathrm{O}+\mathrm{H}_{2} \mathrm{O}_{\text {gas }}{ }^{+} \rightarrow \mathrm{n} \bullet \mathrm{OH}+(\mathrm{n}-1) \mathrm{H} \bullet+\mathrm{H}_{3} \mathrm{O}^{+}\left(\mathrm{H}^{+}\right)
$$

where " $n$ " represents the non-Faraday value[13].

$\mathrm{H} \bullet$ is the conjugate acid form of $\mathrm{eaq}^{-}$.

$$
\mathrm{H} \bullet+\mathrm{H}_{2} \mathrm{O} \leftrightarrows \mathrm{e}_{\mathrm{aq}}{ }^{-}+\mathrm{H}^{+} \quad \mathrm{pKa}=9.6
$$

When $\mathrm{CF}$ is present in the solution, the resulting active species react with $\mathrm{CF}$ via the following reactions $[8,12]$.

$$
\begin{array}{ll}
\cdot \mathrm{H}+\mathrm{CHCl}_{3} \rightarrow \mathrm{Cl}^{-}+\cdot \mathrm{CHCl}_{2}+\mathrm{H}^{+} & k_{3}=1.2 \times 10^{7} \mathrm{M}^{-1} \mathrm{~s}^{-1} \\
\cdot \mathrm{H}+\mathrm{CHCl}_{3} \rightarrow \mathrm{H}_{2}+\cdot \mathrm{CCl}_{3} & k_{4}=2.4 \times 10^{6} \mathrm{M}^{-1} \mathrm{~s}^{-1} \\
\mathrm{e}_{\mathrm{aq}}{ }^{-}+\mathrm{CHCl}_{3} \rightarrow \mathrm{Cl}^{-}+\cdot \mathrm{CHCl}_{2} & k_{5}=3.0 \times 10^{10} \mathrm{M}^{-1} \mathrm{~s}^{-1} \\
\cdot \mathrm{OH}+\mathrm{CHCl}_{3} \rightarrow \mathrm{H}_{2} \mathrm{O}+\cdot \mathrm{CCl}_{3} & k_{6}=5.0 \times 10^{6} \mathrm{M}^{-1} \mathrm{~s}^{-1}
\end{array}
$$

According to reactions $2-5$, the decay of CF can be described by the following 
equation (eq.7):

$$
-\frac{d[\mathrm{CF}]}{d t}=\left(k_{3}+k_{4}\right)[\mathrm{CF}][\bullet \mathrm{H}]+k_{5}[\mathrm{CF}]\left[e_{a q}^{-}\right]+k_{6}[\mathrm{CF}][\bullet \mathrm{OH}]
$$

As shown by reaction 2 , $\mathrm{eaq}^{-}$was predominant at high $\mathrm{pH}$. As a result, the removal of $\mathrm{CF}$ increased with increasing $\mathrm{pH}_{0}$, because the rate constant of reaction 5 is 3 orders of magnitude higher than those of reactions (3) and (4).

In basic conditions, $\bullet \mathrm{OH}$ react with $\mathrm{OH}^{-}$, thereby reducing the recombination between $\bullet \mathrm{OH}$ and $\mathrm{eaq}^{-}{ }^{-}$24].

$$
\begin{aligned}
& \cdot \mathrm{OH}+\mathrm{HO}^{-} \rightarrow \cdot \mathrm{O}^{-}+\mathrm{H}_{2} \mathrm{O} \quad k_{8}=1.3 \times 10^{10} \mathrm{M}^{-1} \mathrm{~s}^{-1} \\
& \cdot \mathrm{OH}+\mathrm{e}_{\mathrm{aq}}{ }^{-} \rightarrow \mathrm{H}_{2} \mathrm{O}+\mathrm{OH}^{-} \quad k_{9}=3.0 \times 10^{10} \mathrm{M}^{-1} \mathrm{~s}^{-1}
\end{aligned}
$$

In basic media, the concentration of $\bullet \mathrm{OH}$ decreased as a result of reaction 8 , which indirectly increased the concentration of $\mathrm{e}_{\mathrm{aq}}{ }^{-}$due to reaction 9 . Although $\bullet \mathrm{OH}$ can also react with $\mathrm{CF}$, the removal of $\mathrm{CF}$ increased because the rate constant of reaction 5 is much higher than that of reaction 6. Therefore, the removal of CF and the generation of $\mathrm{Cl}^{-}$increased with increasing $\mathrm{pH}$ due to reactions 2,8 and 9. It can be observed from the control experiments of Fig.6 that the direct hydrolyses of CF were negligible under the present experimental conditions.

\subsection{Effect of radical scavengers on $\mathrm{CF}$ removal and dechlorination}

In this section, methanol and isopropanol were chosen as the typical $\bullet \mathrm{OH}$ radical scavengers and $\mathrm{H}_{2} \mathrm{O}_{2}$ was selected as a typical $e_{a q}{ }^{-}$scavenger to study the role of the active species played in the CF removal and dechlorination during the GDP treatment [24]:

$$
\cdot \mathrm{OH}+\mathrm{CH}_{3} \mathrm{OH} \rightarrow \mathrm{H}_{2} \mathrm{O}+\cdot \mathrm{CH}_{2} \mathrm{OH} k_{9} \quad k_{10}=9.7 \times 10^{8} \mathrm{M}^{-1} \mathrm{~s}^{-1}
$$




$$
\begin{array}{cr}
\cdot \mathrm{OH}+\left(\mathrm{CH}_{3}\right)_{2} \mathrm{CHOH} \rightarrow \mathrm{H}_{2} \mathrm{O}+\cdot\left(\mathrm{CH}_{3}\right)_{2} \mathrm{COH} & k_{11}=1.9 \times 10^{9} \mathrm{M}^{-1} \mathrm{~s}^{-1} \\
\mathrm{e}_{\mathrm{aq}}{ }^{-}+\mathrm{H}_{2} \mathrm{O}_{2} \rightarrow \cdot \mathrm{OH}+\mathrm{OH}^{-} & k_{12}=2.0 \times 10^{10} \mathrm{M}^{-1} \mathrm{~s}^{-1}
\end{array}
$$

Removal of $\mathrm{CF}$ and generation of $\mathrm{Cl}^{-}$, and $\left[\mathrm{Cl}^{-}\right] /\left([\mathrm{CF}]_{0}-[\mathrm{CF}]\right)$ under different concentrations of methanol, isopropanol and $\mathrm{H}_{2} \mathrm{O}_{2}$, with 60 min of GDP treatment are shown in Figs.7a and b, respectively.

\section{(Fig.7)}

As indicated in Fig.7a, both the removal of $\mathrm{CF}$ and the generation of $\mathrm{Cl}^{-}$increased with the presence of $\bullet \mathrm{OH}$ scavengers. This phenomenon can be explained by the fact that $\bullet \mathrm{OH}$ radicals and $\mathrm{H} \bullet$ atoms (or $\mathrm{e}_{\mathrm{aq}}{ }^{-}$) resulting from GDP react mutually to form $\mathrm{H}_{2} \mathrm{O}$ :

$$
\cdot \mathrm{H} / \mathrm{e}_{\mathrm{aq}}{ }^{-}+\cdot \mathrm{OH} \rightarrow \mathrm{H}_{2} \mathrm{O} / \mathrm{OH}^{-} \quad k_{13}=3.0 \times 10^{10} \mathrm{M}^{-1} \mathrm{~s}^{-1}
$$

In the presence of methanol or isopropanol, $\bullet \mathrm{OH}$ radicals reacted with them, and the concentration of $\bullet \mathrm{OH}$ radicals decreased accordingly, which in turn increased the concentration of $\mathrm{e}_{\mathrm{aq}}{ }^{-}$( $\mathrm{or} \cdot \mathrm{H}$ ) by inhibiting the reaction 13. From Fig.7, we can also see that isopropanol was more efficient than methanol in enhancing the CF removal and the $\mathrm{Cl}^{-}$generation. Two reasons explain the phenomena. On the one hand, isopropanol is a more efficient $\bullet \mathrm{OH}$ scavenger (reactions 10 and 11 ). On the other, the organic radicals resulting from reaction 11 can also react with CF via reaction 14 [25]:

$$
\cdot\left(\mathrm{CH}_{3}\right)_{2} \mathrm{COH}+\mathrm{HCCl}_{3} \rightarrow\left(\mathrm{CH}_{3}\right)_{2} \mathrm{CO}+\cdot \mathrm{CHCl}_{2}+\mathrm{Cl}^{-}+\mathrm{H}^{+}
$$

Consequently, isopropanol is a more efficient accelerator than methanol in the $\mathrm{CF}$ removal and its dechlorination. 
As also shown in Fig.7a, the removal of $\mathrm{CF}$ and the generation of $\mathrm{Cl}^{-}$decreased with the presence of $\mathrm{H}_{2} \mathrm{O}_{2}$. This is because the $\mathrm{H}_{2} \mathrm{O}_{2}$ competes with $\mathrm{CF}$ for the e ${ }_{\mathrm{aq}}{ }^{-}$, and the removal of $\mathrm{CF}$ and the generation of $\mathrm{Cl}^{-}$decreased accordingly. The present studies further demonstrated that $\mathrm{e}_{\mathrm{aq}}{ }^{-}$played a dominant role in the removal of $\mathrm{CF}$.

It can be observed from Fig. $7 \mathrm{~b}$ that the values of the ratio between the amount of the generated $\mathrm{Cl}^{-}$and that of the $\mathrm{CF}$ eliminated were ca. 2.4 in the cases of $\bullet \mathrm{OH}$ radical scavengers, which were lower than that without organic additive (ca. 2.8). This means that the increase of the CF removal was more than that of its dechlorination in the presence of organic additives. As shown by reaction 12 , the concentration of $\bullet \mathrm{H}$ atoms increased in the presence of $\bullet \mathrm{OH}$ radical scavengers, which would favor the combination reaction between $\cdot \mathrm{H}$ atoms and dichloromethyl radicals $\left(\cdot \mathrm{CHCl}_{2}\right)$ and the hydrolysis of the $\cdot \mathrm{CHCl}_{2}$ radicals would be inhibited (reaction 21 in section 3.5). As a result, the ratio between the amount of the generated $\mathrm{Cl}^{-}$and that of the $\mathrm{CF}$ eliminated decreased. In practice, real wastewater often contains various other organics that consume the $\bullet \mathrm{OH}$ radicals. The present studies showed that GDP is very applicable in the removal of $\mathrm{CF}$ from real water. This further demonstrated that the reducing radicals other than the oxidative $\cdot \mathrm{OH}$ radicals played important roles in the removal and the dechlorination of CF during GDP treatment.

\subsection{Intermediate byproducts formation and possible reaction mechanism}

In order to understand the mineralization mechanism of $\mathrm{CF}$, GC and IC were used to monitor the intermediate byproducts. Fig. 8 shows concentration variations of the 
major intermediate byproducts formed during GDP treatment at $\mathrm{pH}_{0}$ 7.0.

\section{(Fig.8)}

As shown in Fig.8, formic acid (FA), oxalic acid (OA) and dichloromethane $\left(\mathrm{CH}_{2} \mathrm{Cl}_{2}, \mathrm{DCM}\right)$ are the major intermediate byproducts. The yields of both FA and OA increased to the maximums at $120 \mathrm{~min}$ and then decreased gradually. On the other hand, the yield of DCM increased smoothly within $30 \mathrm{~min}$ and then decreased gradually and finally disappeared. It is noted that tetrachloroethylene $\left(\mathrm{C}_{2} \mathrm{Cl}_{4}\right)$ was also detected by GC at 30 min of the discharge. However, its concentration was too small to be quantitatively determined. FA may be formed by the hydrolysis and subsequent oxidation of $\cdot \mathrm{CHCl}_{2}$ radicals [8]:

$$
\begin{aligned}
& \cdot \mathrm{CHCl}_{2}+\mathrm{H}_{2} \mathrm{O} \rightarrow \cdot \mathrm{CHO}+2 \mathrm{HCl} \\
& \cdot \mathrm{CHO}+\mathrm{CHCl}_{3}+\mathrm{H}_{2} \mathrm{O} \rightarrow \cdot \mathrm{CHCl}_{2}+\mathrm{HCOOH}+\mathrm{HCl}
\end{aligned}
$$

It should be noted that the direct hydrolysis of $\bullet \mathrm{CCl}_{3}$ radicals from reaction 6 may also contribute to the formation of FA (via reactions 17 and 18) [8]:

$$
\begin{array}{r}
\cdot \mathrm{CCl}_{3}+2 \mathrm{H}_{2} \mathrm{O} \rightarrow \cdot \mathrm{COOH}+3 \mathrm{HCl} \\
\cdot \mathrm{COOH}+\cdot \mathrm{COOH} \rightarrow \mathrm{HCOOH}+\mathrm{CO}_{2}
\end{array}
$$

OA was yielded by the combination of the $\cdot \mathrm{COOH}$ radicals:

$$
\cdot \mathrm{COOH}+\cdot \mathrm{COOH} \rightarrow \mathrm{H}_{2} \mathrm{C}_{2} \mathrm{O}_{4}
$$

In practice, when FA was used as a starting material, OA was also yielded. This means that $\mathrm{OA}$ might result from FA via oxidation by $\bullet \mathrm{OH}$ radicals:

$$
\mathrm{HCOOH}+2 \cdot \mathrm{OH} \rightarrow \mathrm{H}_{2} \mathrm{C}_{2} \mathrm{O}_{4}+2 \mathrm{H}_{2} \mathrm{O}
$$

DCM was formed as a result of combination reaction between $\cdot \mathrm{CHCl}_{2}$ radicals 
and $\mathrm{H} \bullet$ atoms:

$$
\mathrm{H} \bullet+\cdot \mathrm{CHCl}_{2} \rightarrow \mathrm{CH}_{2} \mathrm{Cl}_{2}
$$

Reaction 21 has been confirmed by the fact that the yield of DCM increased in the presence of $\bullet \mathrm{OH}$ radical scavengers (not shown in the figure).

$\mathrm{C}_{2} \mathrm{Cl}_{4}$ was formed by the combination of dichlrocarbene $\left(: \mathrm{CCl}_{2}\right)$ :

$$
: \mathrm{CCl}_{2}+: \mathrm{CCl}_{2} \rightarrow \mathrm{C}_{2} \mathrm{Cl}_{4}
$$

And : $\mathrm{CCl}_{2}$ may be formed via the following reactions [26]:

$$
\begin{aligned}
& \cdot \mathrm{CHCl}_{2}+\cdot \mathrm{OH} \rightarrow \mathrm{CHCl}_{2} \mathrm{OH} \\
& \mathrm{CHCl}_{2} \mathrm{OH} \rightarrow \mathrm{H}_{2} \mathrm{O}+: \mathrm{CCl}_{2}
\end{aligned}
$$

By comparing Figs.2, 3 and 8, it can be found that the amount of organic byproducts is minor in comparison with that of $\mathrm{CF}$ removed, and the ratio between the amount of the generated $\mathrm{Cl}^{-}$and that of the CF eliminated was close to 3:1, which cannot be explained just by reactions 15-24 (if this is the case, much more intermediate byproducts than those shown in Fig. 8 would be formed). This may be due to the oxygen enhanced hydrolysis of the chloromethyl radicals such as [23, 28]:

$$
\begin{aligned}
& \cdot \mathrm{CHCl}_{2}+\mathrm{O}_{2} \rightarrow \mathrm{CHCl}_{2} \mathrm{O}_{2} \bullet \quad k=3.0 \times 10^{10} \mathrm{M}^{-1} \mathrm{~s}^{-1} \\
& \cdot \mathrm{CHCl}_{2} \mathrm{O}_{2}+\mathrm{H}_{2} \mathrm{O} \rightarrow 2 \mathrm{HCl}+\cdot \mathrm{OH}+\mathrm{CO}_{2} \\
& \cdot \mathrm{CCl}_{3}+\mathrm{O}_{2} \rightarrow \mathrm{CCl}_{3} \mathrm{O}_{2} \bullet \quad k_{27}=3.3 \times 10^{9} \mathrm{M}^{-1} \mathrm{~s}^{-1} \\
& \cdot \mathrm{CCl}_{3} \mathrm{O}_{2}+2 \mathrm{H}_{2} \mathrm{O} \rightarrow 3 \mathrm{HCl}+\mathrm{HO}_{2} \bullet+\mathrm{CO}_{2}
\end{aligned}
$$

The concentration of oxygen in air-saturated solutions is approximately $0.25 \mathrm{mM}$. In the presence of oxygen, the chloromethyl radicals react rapidly with it to form the corresponding peroxyl radicals. The resulting peroxyl radicals undergo rapid 
hydrolyses, leading to the formation of $\mathrm{CO}_{2}$ and $\mathrm{Cl}^{-}$. As reactions 26 and 28 are considerably faster than reactions 15,16 and 17, less FA and OA were yielded.

It should be noted that hexachloroethane $\left(\mathrm{C}_{2} \mathrm{Cl}_{6}\right)$ was not detected in the present investigation, possibly because the trichloromethyl radicals $\left(\cdot \mathrm{CCl}_{3}\right)$ produced in reactions 4 and 6 were trace and the resulting radicals were rapidly hydrolyzed into $\mathrm{Cl}^{-}$and $\mathrm{CO}_{2}$ in the presence of oxygen before combining into $\mathrm{C}_{2} \mathrm{Cl}_{6}[8]$.

No chloromethane $\left(\mathrm{CH}_{3} \mathrm{Cl}\right)$ was detected in the present experiment, even when 1.0 mM DCM was subjected to GDP. However, $\mathrm{CH}_{3} \mathrm{Cl}$ can be detected when $1.0 \mathrm{mM}$ DCM and $1.0 \mathrm{mM}$ isopropanol were both exposed to GDP. This means that $\mathrm{H}_{3} \mathrm{CCl}$ might be formed in the mineralization processes of $\mathrm{CF}$.

When DCM and $\mathrm{C}_{2} \mathrm{Cl}_{4}$ were used as the starting materials, $\mathrm{Cl}^{-}$and $\mathrm{CO}_{2}$ were eventually and quantitatively generated. This demonstrated that the chlorinated byproducts can also be efficiently converted into $\mathrm{Cl}^{-}$and $\mathrm{CO}_{2}$ by GDP.

Based on the above observations, the probable reaction mechanism for $\mathrm{CF}$ dechlorination and decomposition by GDP is proposed in Scheme 1.

\section{(Scheme 1)}

It can be seen from Scheme 1 that the CF mineralization in GDP can be divided into three main steps: I) initiation of the reaction, II) hydrolysis of the chloromethyl radicals and III) oxidation of the organic acids. At the initial stage, CF preferentially react with hydrated electrons or $\bullet \mathrm{H}$ atoms to form the corresponding dichloromethyl radicals with liberation of $\mathrm{Cl}^{-}$(or $\mathrm{HCl}$ ). In the second process, the resulting dichloromethyl radicals directly hydrolyzed to carboxyl radicals and $\mathrm{HCl}$ or subjected 
to oxygen enhanced hydrolyses to form $\mathrm{CO}_{2}$ and $\mathrm{HCl}$. The dichloromethyl radicals can also react with $\cdot \mathrm{H}$ atoms or $\bullet \mathrm{OH}$ radicals to form trace amount of chlorinated organic byproducts such as DCM and $\mathrm{C}_{2} \mathrm{Cl}_{4}$. Subsequently, the resulting carboxyl radicals react with each other to form FA and OA. In the last step, the organic acids react with $\bullet \mathrm{OH}$ radicals and are completely oxidized to $\mathrm{CO}_{2}$ and $\mathrm{H}_{2} \mathrm{O}$. At the same time, the traces of the chlorinated organic intermediate byproducts are also mineralized to inorganic carbon and $\mathrm{Cl}^{-}(\mathrm{HCl})$ under the action of GDP.

\subsection{Energy efficiency}

Energy efficiency is an important indicator for comparing different techniques and for evaluating its potential industrial applications. In this study, the energy efficiency for $\mathrm{CF}$ removal $\left(J_{\mathrm{CF}}\right)$ is defined the quantity of $\mathrm{CF}$ removed per unit energy input, which can be formulated as follows:

$$
J_{\mathrm{CF}}=\frac{\frac{1}{2} C_{0} V o l}{U I t_{1 / 2}}
$$

where $C_{0}$ is the initial CF concentration in mol/L, $V o l$ is the liquid volume in $\mathrm{L}, U$ is the applied voltage in $\mathrm{V}, I$ is the current in $\mathrm{A}$, and $t_{1 / 2}$ is the reaction time required for removing half of the initial CF molecules. Table 1 shows the energy efficiencies of the present work and some typical competitive methods.

\section{(Table 1)}

It can be seen that the energy efficiency of CF removal by GDP is in the same order of magnitude to that of ultrasonic oxidation and much higher that those of $\mathrm{TiO}_{2}$ photocatalysis, especially in basic media and in the presence of hydroxyl radical 
scavengers. These demonstrated that GDP is a competitive process for CF removal.

\section{Conclusions}

CF can be efficiently dechlorinated and decomposed by GDP. The removal and the dechlorination of $\mathrm{CF}$ increased with increasing $\mathrm{pH}$ (from 2.0 to 11.0) and with addition of hydroxyl radical scavengers. Formic acid, oxalic acid and dichloromethane were the major intermediate byproducts. These byproducts can be fully mineralized to carbon dioxide and hydrochloric acid. Hydrated electrons were the main active species for initiation of the reaction, and $\bullet \mathrm{OH}$ radicals were the ones for oxidation of the organic radicals and intermediate byproducts. Hydrolyses of the chloromethyl radicals and the chloromethylperoxyl radicals contributed much in the mineralization of the organic chlorine. Further studies on the mechanistic aspects are underway.

\section{Acknowledgements}

This work was supported by the National Science Foundation of China (11005014, 51008262), the State Scholarship Fund of China (201406575032), the Natural Science Foundation of Fujian province, China (2015J01651), and the Science and Technology Plan Project of Xiamen City (3502Z20133040). 


\section{References}

[1] M. Rossberg, W. Lendle, G. Pfleiderer, A. Tögel, E. Dreher, E. Langer, H. Rassaerts, P. Kleinschmidt, H. Strack, R. Cook, U. Beck, K. Lipper, T. Torkelson, E. Löser, K. Beutel, T. Mann, Chlorinated Hydrocarbons, in Ullmann's Encyclopedia of Industrial Chemistry, 2006,Wiley-VCH, Weinheim.

[2] R. F. Christman, D. L. Norwood, G. S. Millngton, Identity and yields of major halogenated products of aquatic fulvic acid chlorination. Environ. Sci. Technol. 17 (1983) 625-628.

[3] P. Chambon, M. Taveau, M. Morin, R. Chambon, J. Vial, Survey of trihalomethane levels in Rhône-Alps water supplies. Estimates on the formation of chloroform in wastewater treatment plants and swimming pools, Water Res. 17 (1983) 65-69.

[4] http://www.epa.gov/iris/toxreviews/0025tr.pdf

[5] D. M. Bagley, M. Lalonde, V. Kaseros, K. E. Stasiuk, B. E. Sleep, Acclimation of anaerobic systems to biodegrade tetrachloroethene in the presence of carbon tetrachloride and chloroform, Water Res. 34 (2000) 171-178.

[6] J. Q. Adams, R. M. Clark, Evaluating the costs of packed-tower aeration and GAC for controlling selected organics, J. Am. Water Works Assoc. 1991, 83(1): 49-57.

[7] W. Z. Tang, S. Tassos, Oxidation kinetics and mechanisms of trihalomethanes by Fenton's reagent, Water Res. 31(1997) 1117-1125.

[8] B. J. Rezansoff, K. J. Mccallum, and R. J. Woods, Radiolysis of aqueous chloroform solutions, Can. J. Chem. 48 (1970) 271-276.

[9] H. Shemer, N. Narkis, Trihalomethanes aqueous solutions sono-oxidation, Water Res. 39 (2005) 2704-2710.

[10] C. Kormann, D.W. Bahnemann, and M.R. Hoffmann, Photolysis of chloroform and other organic molecules in aqueous $\mathrm{TiO}_{2}$ suspensions, Environ. Sci. Technol. 25 
(1991) 494-500.

[11] W. Choi, M.R. Hoffmann, Novel photocatalytic mechanisms for $\mathrm{CHCl}_{3}, \mathrm{CHBr}_{3}$, and $\mathrm{CCl}_{3} \mathrm{CO}_{2}{ }^{-}$degradation and the fate of photogenerated trihalomethyl radicals on $\mathrm{TiO}_{2}$. Environ. Sci. Technol. 31 (1997) 89-95.

[12] W. J. Cooper, E. Cadavid, M. G. Nickelsen, K. Lin, C. N. Kuruce, T. D. Waite, Removing THMs from drinking water using high-energy electron-beam irradiation, J. Am. Water Works Assoc. 85 (1993) 106-112.

[13] K. S. Susanta, S. Rajeshwar, K. S. Ashok, A study on the origin of non-Faradaic behavior of anodic contact glow discharge electrolysis, J. Electrochem. Soc. 145(1998) $2209-2213$.

[14] X. Wang, M. Zhou, X. Jin, Application of glow discharge plasma for wastewater treatment. Electrochimica Acta, 83(2012) 501-512.

[15] A. T. Bullock, D. L. Gavin, M. D. Ingram, Electron spin resonance detection of spin-trapped radicals formed during the glow-discharge electrolysis of aqueous solutions. J. Chem. Soc., Faraday Trans. 76 (1980) 648-653.

[16] Y. Liu, B. Sun, L. Wang, D. Wang, Characteristics of light emission and radicals formed by contact glow discharge electrolysis of an aqueous solution, Plasma Chem. Plasma Proces. 32 (2012) 359-368.

[17] J. Goodman, A. Hickling, B. Schlfield, The yield of hydrated electrons in glow discharge electrolysis, J. Electroanal. Chem. Interfac. 48 (1973) 319-322.

[18] J. Gao, X. Wang, Z. Hu, H. Deng, J. Hou, X. Lu, J. Kang, Plasma degradation of dyes in water with contact glow discharge electrolysis, Water Res. 37 (2003) 267-272. [19] M. Tezuka, M. Iwasaki Plasma induced degradation of chlorophenols in an aqueous solution, Thin Solid Films, 316 (1998) 123-126.

[20] Y. Liu, D. Wang, B. Sun, X. Zhu, Aqueous 4-nitrophenol decomposition and hydrogen peroxide formation induced by contact glow discharge electrolysis, J. 
Hazard. Mater. 181(2010) 1010-1015.

[21] K Gai, Plasma-induced degradation of diphenylamine in aqueous solution, $J$. Hazard. Mater. 146 (2007) 249-254.

[22] L. Wang, H. Zeng, Y. Xin, Dechlorination and decomposition of trichloroacetic acid by glow discharge plasma in aqueous solution, Electrochimica Acta. 115 (2014) $332-336$.

[23] L. Wang, X. Jiang, Plasma-induced reduction of chromium (VI) in an aqueous solution, Environ. Sci. Technol. 42 (2008) 8492-8497.

[24] G. V. Buxton, C. L. Greenstock, W. P. Helman, A. B. Ross, Critical review of rate constants for reactions of hydrated electrons, hydrogen atoms and hydroxyl radicals. Phys. Chem. Ref. Data, 17 (1998) 513-886.

[25] R. L. Willson, T. F. Slater, Carbon tetrachloride and biological damage: pulse radiolysis studies of associated free radical reactions. Fast Processes in Radiation Chemistry and Biology, Proceedings of the fifth LH Gray Conference, G.E. Adams, E.M. Fielden and B.D. Michael (eds.), The Institute of Physics and John Wiley \& Sons. (1975) 147-161.

[26] P. Dowideit, R. Mertens, C. von Sonntag, Non-hydrolytic decay of Formyl Chloride into $\mathrm{CO}$ and $\mathrm{HCl}$ in aqueous solution, J. Am. Chem. Soc. 118 (1996) $11288-11292$.

[27] B. Lesigne, L. Gilles, R. J. Woods, Spectra and decay of trichloromethyl radicals in aqueous solution, Can. J. Chem. 52(1974) 1135-1139.

[28] J. Mönig, D. Bahnemann, K. -D. Asmus, One electron reduction of $\mathrm{CCl}_{4}$ in oxygenated aqueous solutions: $\mathrm{A} \mathrm{CCl}_{3} \mathrm{O}_{2}{ }^{-}$free radical mediated formation of $\mathrm{Cl}^{-}$and $\mathrm{CO}_{2}$, Chem. Biol. Interact. 47 (1983) 15-27.

[29]H. Hung, M. Hoffmann, Kinetics and mechanism of the sonolytic degradation of chlorinated hydrocarbons: frequency effects, J. Phys. Chem. A, 103 (1999) 2734-2739. 
Table 1. Comparison of energy efficiency of GDP with those of other competitive technologies for CF removal

\begin{tabular}{|c|c|c|c|c|}
\hline$C_{0}(\mathrm{mM})$ & $\begin{array}{l}\text { Method and typical } \\
\text { reaction conditions }\end{array}$ & $\begin{array}{c}J_{\mathrm{CF}} \\
\left(10^{-10} \mathrm{~mol} / \mathrm{J}\right)\end{array}$ & $\begin{array}{l}\text { Removal efficiency at } \\
60 \text { min treatment }(\%)\end{array}$ & References \\
\hline 0.84 & GDP $50 \mathrm{~W} \mathrm{pH}_{0} 7.0$ & 2.1 & 37.1 & This work \\
\hline 0.84 & GDP $50 \mathrm{~W} \mathrm{pH} 11.0$ & 3.4 & 42.5 & This work \\
\hline 0.84 & $\begin{array}{l}\text { GDP } 50 \mathrm{~W} \mathrm{pH}_{0} 11.0 \\
0.16 \mathrm{M} \text { isopropanol }\end{array}$ & 8.5 & 88.2 & This work \\
\hline 6.0 & $\begin{array}{l}\text { Photocatalysis } 910 \mathrm{~W} \\
\mathrm{pH}_{0} 12.0,0.5 \mathrm{~g} / 1 \mathrm{TiO}_{2}\end{array}$ & 0.064 & 8.4 & [11] \\
\hline 0.084 & $\begin{array}{l}\text { Sonolytic oxidation } \\
18.4 \mathrm{~W} / 1\end{array}$ & 1.26 & 13.2 & [9] \\
\hline 0.2 & Sonolytic oxidation $35 \mathrm{~W}$ & 3.6 & 75.6 & [29] \\
\hline
\end{tabular}




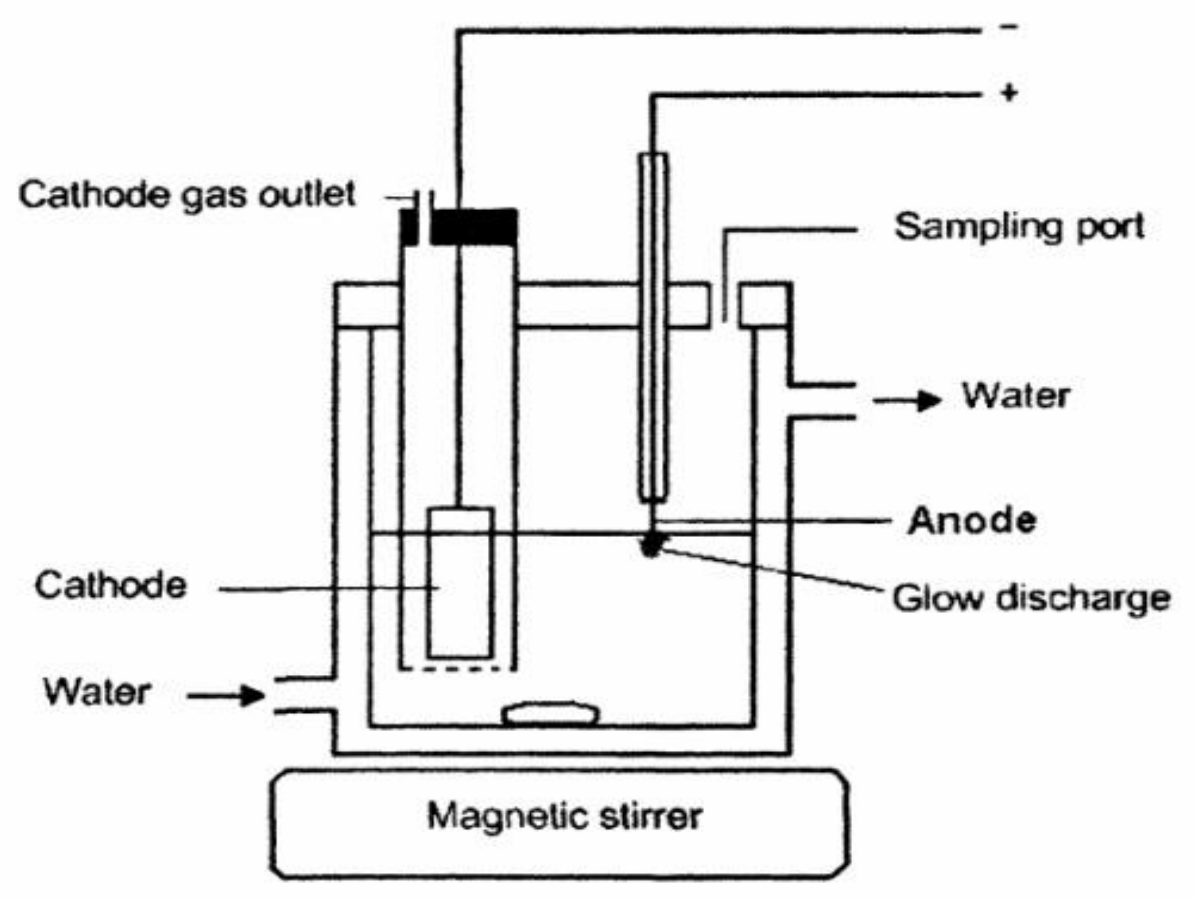

Fig.1. GDP reactor for dechlorination and decomposition of CF 


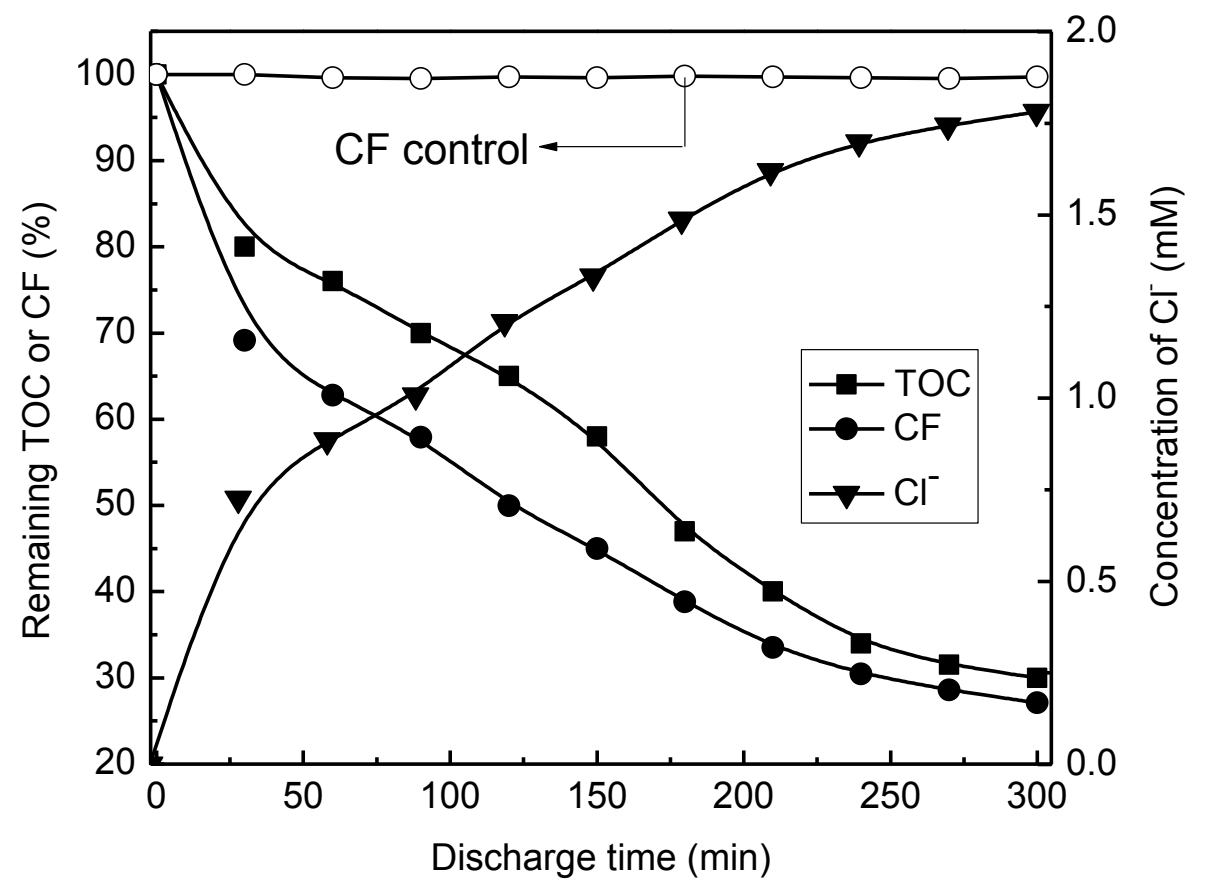

Fig.2. Concentration variations of CF, TOC and $\mathrm{Cl}^{-}$during GDP treatment (voltage, $500 \mathrm{~V}$; average current, $100 \mathrm{~mA}$; solution volume, $150 \mathrm{ml}$; $\left.[\mathrm{CF}]_{0}, 0.84 \mathrm{mM} ; \mathrm{pH}_{0}, 7.0\right)$ 


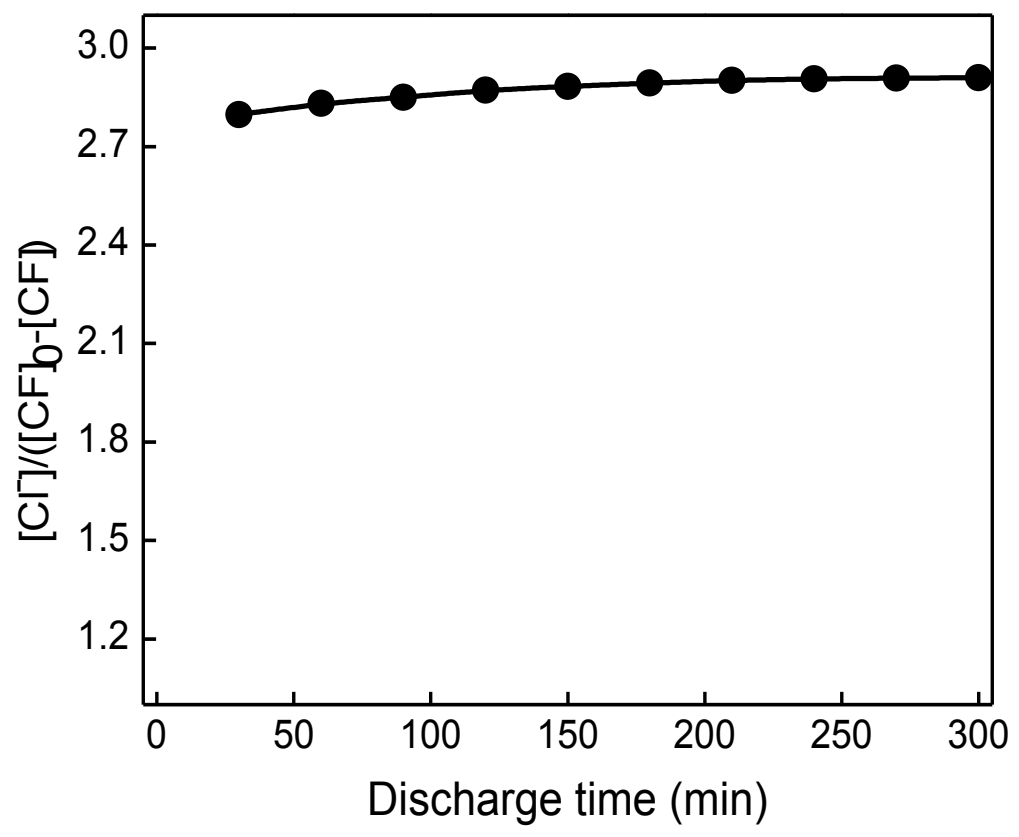

Fig.3. Variation of $\left[\mathrm{Cl}^{-}\right] /\left([\mathrm{CF}]_{0}-[\mathrm{CF}]\right)$ during GDP treatment (voltage, $500 \mathrm{~V}$; average current, $100 \mathrm{~mA}$; solution volume, $150 \mathrm{ml}$; [CF $]_{0}, 0.84 \mathrm{mM}$; pHo,7.0) 


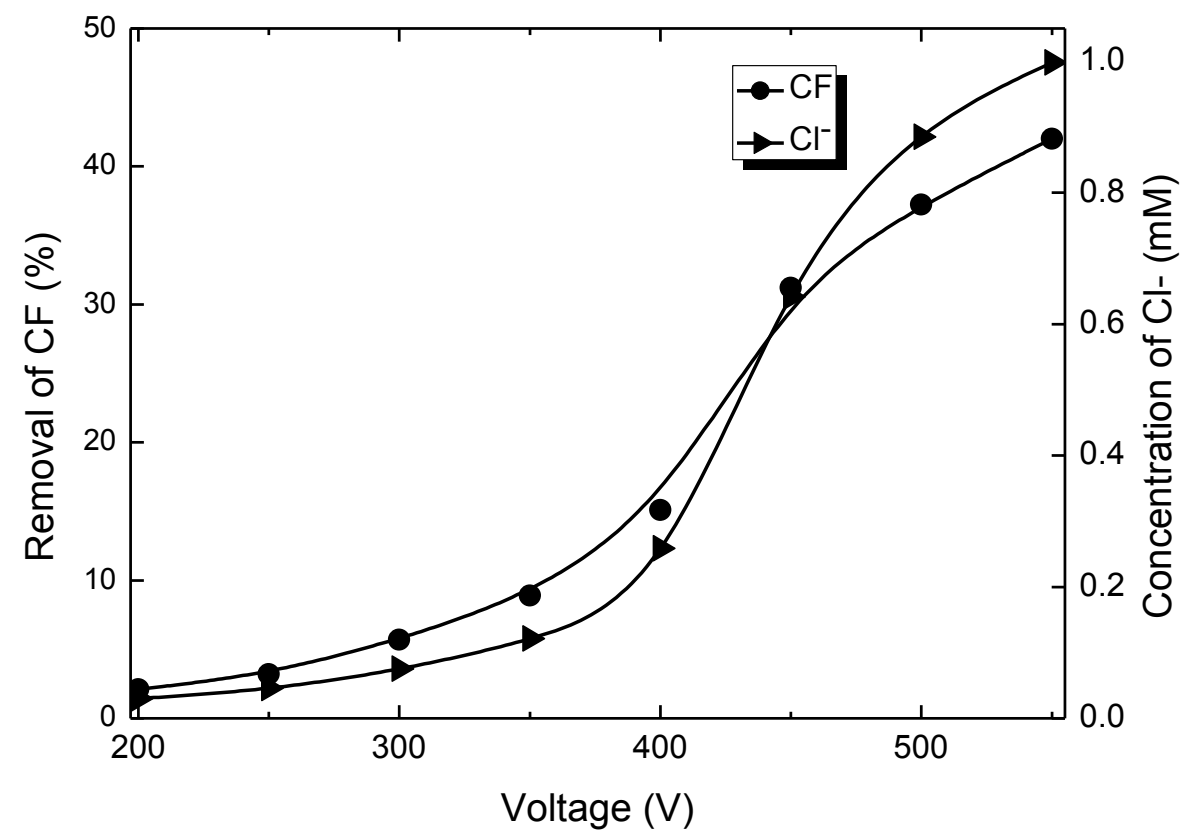

Fig.4. Effect of applied voltage on the removal of $\mathrm{CF}$ and the generation of $\mathrm{Cl}^{-}$with $60 \mathrm{~min}$ of GDP treatment (current, $100 \mathrm{~mA}$; solution volume, $150 \mathrm{ml}$; $[\mathrm{CF}]_{0}, 0.84 \mathrm{mM}$; $\left.\mathrm{pH}_{0}, 7.0\right)$ 


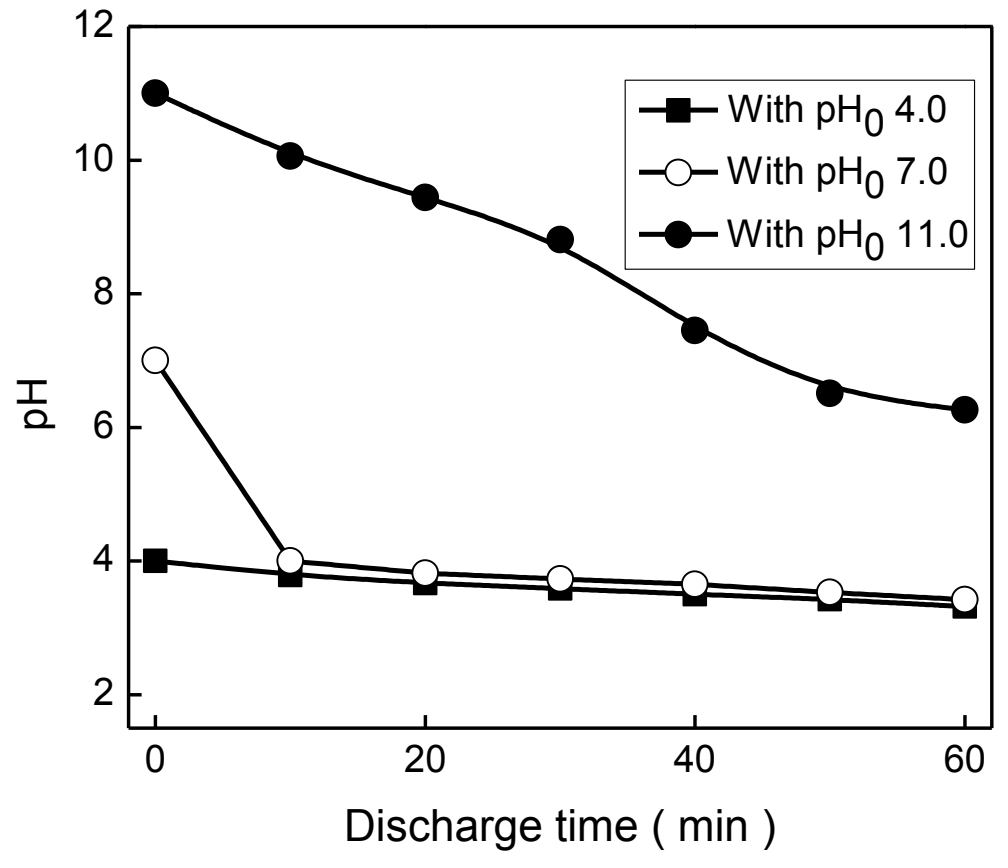

Fig.5. Variation of $\mathrm{pH}$ during GDP treatment under different $\mathrm{pH}_{0}$ (voltage, $500 \mathrm{~V}$; current, $100 \mathrm{~mA}$; solution volume, $150 \mathrm{ml}$; $[\mathrm{CF}]_{0}, 0.84 \mathrm{mM}$ ) 


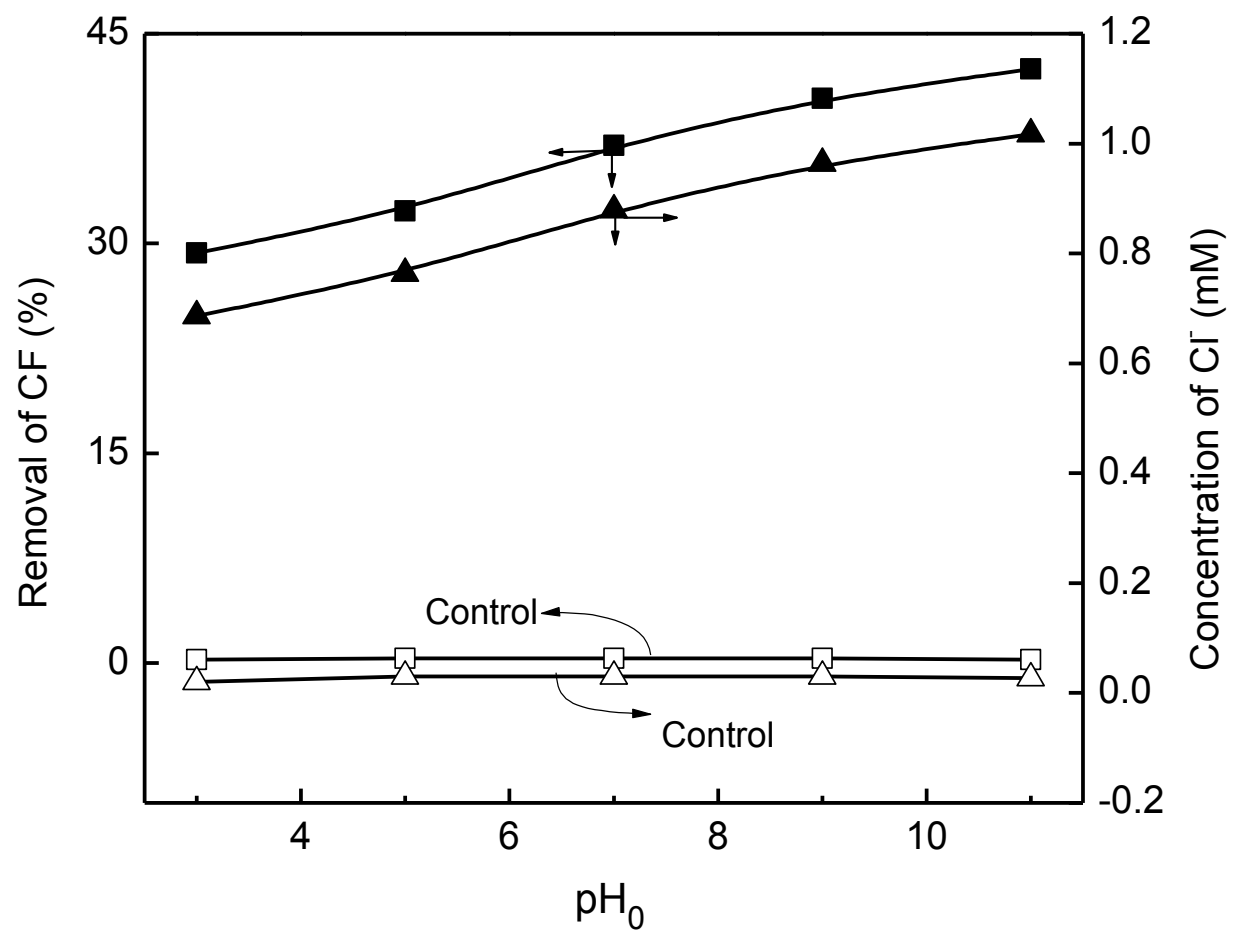

Fig.6. Effect of $\mathrm{pH}_{0}$ on the removal of $\mathrm{CF}$ and the generation of $\mathrm{Cl}^{-}$with 60 min of GDP treatment (voltage, $500 \mathrm{~V}$; current, $100 \mathrm{~mA}$; solution volume, $150 \mathrm{ml}$; $[\mathrm{CF}]_{0}$, $0.84 \mathrm{mM})$ 

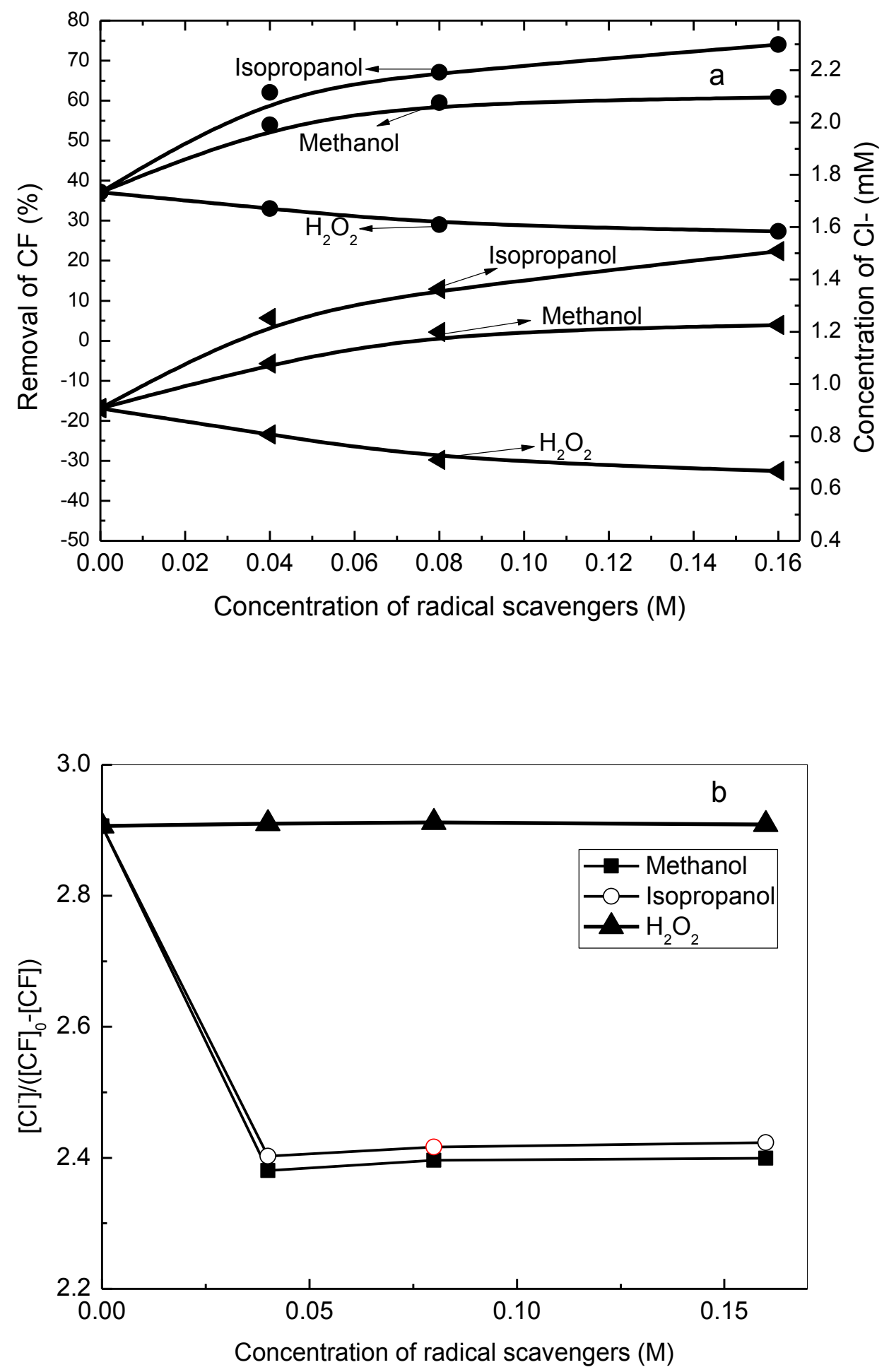

Fig.7. Effect of organic additives on the removal of $\mathrm{CF}$ and generation of $\mathrm{Cl}^{-}$(a) and $\left[\mathrm{Cl}^{-}\right] /\left([\mathrm{CF}]_{0}-[\mathrm{CF}]\right)(\mathrm{b})($ voltage, $500 \mathrm{~V}$; current, $100 \mathrm{~mA}$; solution volume, $150 \mathrm{ml}$; discharge time, $\left.60 \mathrm{~min} ;[\mathrm{CF}]_{0}, 0.84 \mathrm{mM} ; \mathrm{pH}_{0}, 7.0\right)$ 


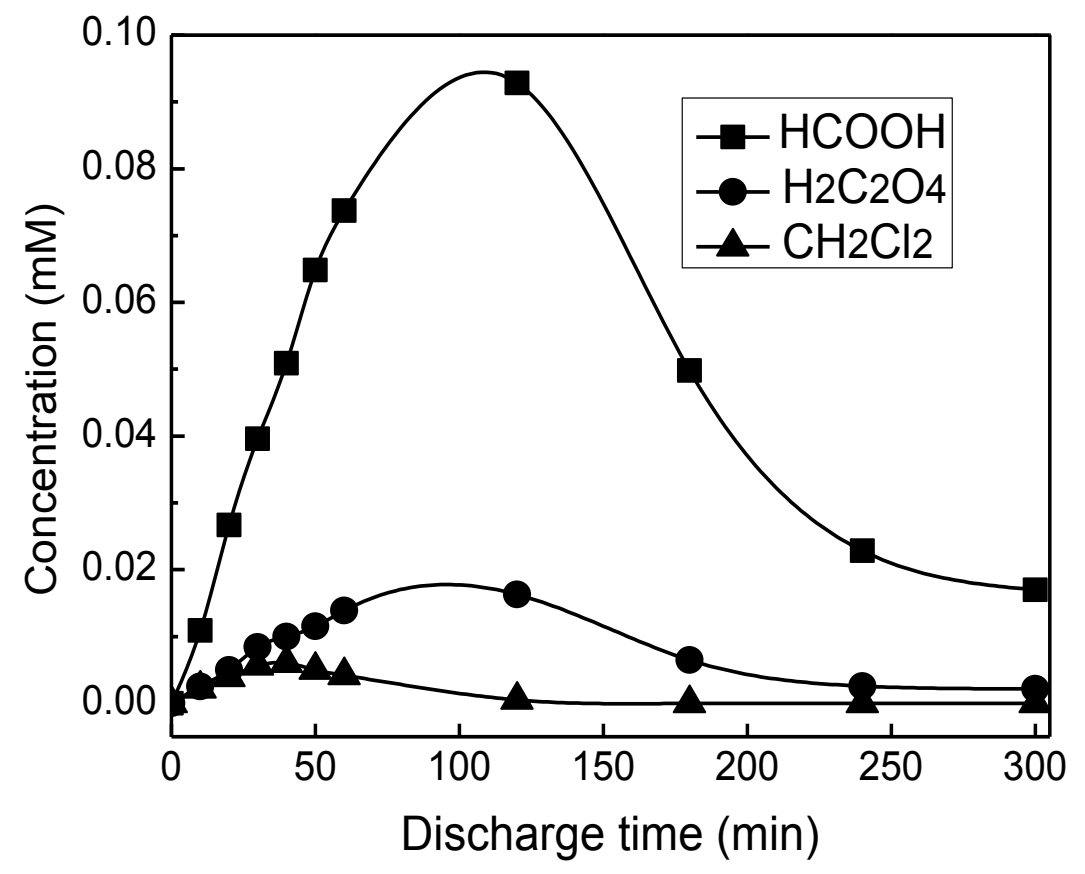

Fig.8. Intermediate byproducts formed during GDP treatment (voltage, $100 \mathrm{~V}$; current, $100 \mathrm{~mA}$; solution volume, $150 \mathrm{ml}$; $[\mathrm{CF}]_{0}, 0.84 \mathrm{mM} ; \mathrm{pH}_{0}, 7.0$ ) 


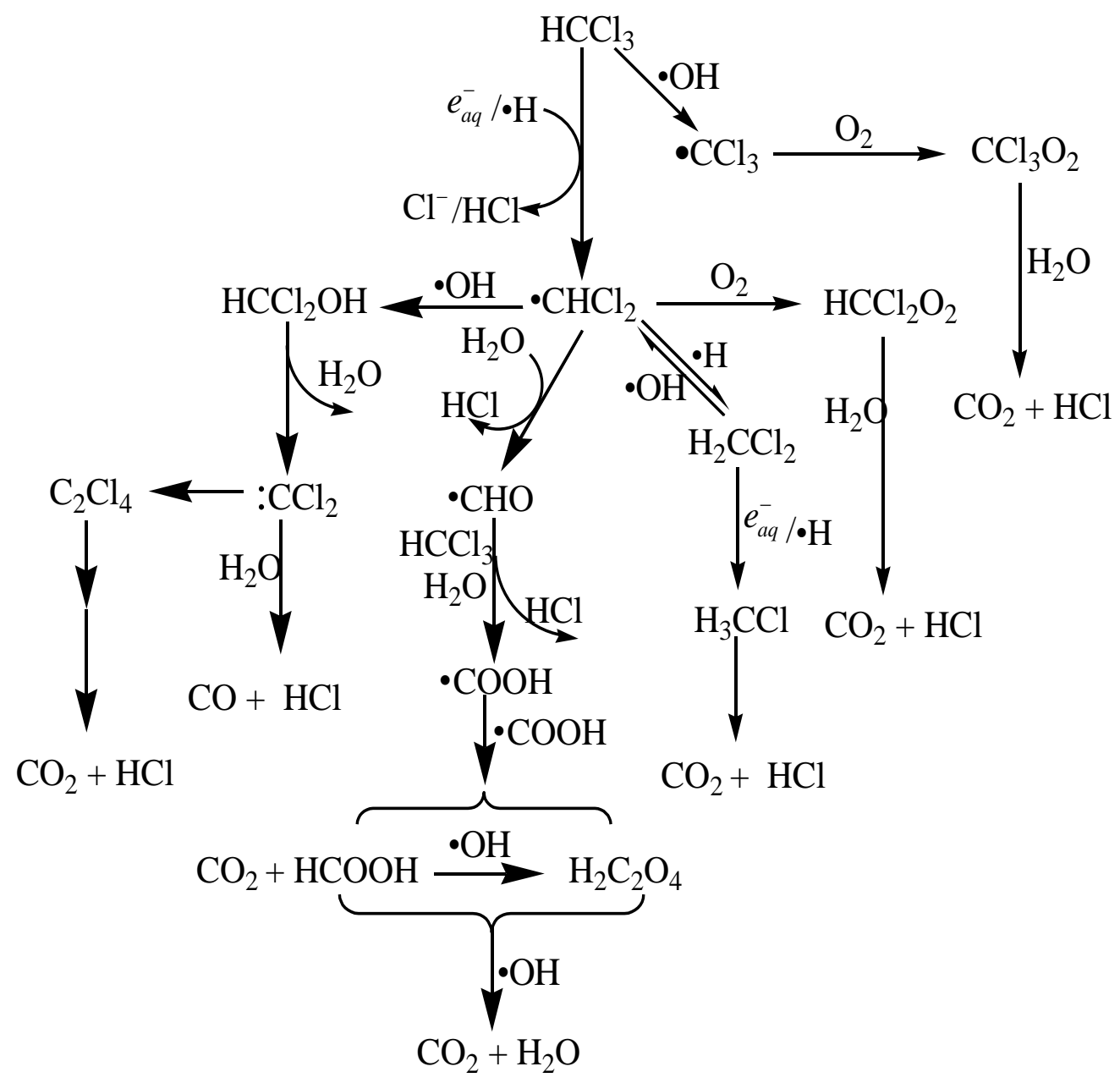

Scheme 1 Proposed reaction mechanism for CF mineralization in GDP 